\title{
Prevalence, and Associated Factors of tobacco smoking among adults in the United Arab Emirates; Results from National Health Survey
}

Hira Abdul Razzak ( $\nabla$ hiraarazzak@gmail.com )

Ministry of Health and prevention https://orcid.org/0000-0001-6393-6680

Ahmad Qawas

Ministry of Health and Prevention

Marwa Mujahed

Ministry of Health and Prevention

Alya Harbi

Ministry of Health and Prevention

\section{Research}

Keywords: Smoking, Tobacco, Prevalence, National Health Survey, United Arab Emirates

Posted Date: July 29th, 2020

DOI: https://doi.org/10.21203/rs.3.rs-49717/v1

License: (a) (i) This work is licensed under a Creative Commons Attribution 4.0 International License.

Read Full License

Version of Record: A version of this preprint was published at Journal of Public Health on May 4th, 2021. See the published version at https://doi.org/10.1007/s10389-021-01571-5. 


\section{Abstract}

Background: Cigarette smoking is one of the major public health concern and is the primary cause of preventable illness and premature death. Tobacco use, including secondary smoking, is a major contributing factor to morbidity and mortality across UAE. This study examined the prevalence, and associated factors of tobacco smoking among adults living in the United Arab Emirates (UAE). The study further aims to study the socioeconomic determinants such as employment, education and income of the UAE population with respect to the status of smoking.

Methods A population-based survey of adults aged 18+ was undertaken. Around 10,000 randomly selected Households across all 7 Emirates were selected to yield representative data. A total of 8188 adults (18 years and above) participated in the national health survey. The overall response rate was $87 \%$ among adult participants.

Results Overall, the prevalence of current smoking was $9.1 \%$ among the selected population whereas, 0.8 $\%$ of the respondents smoked tobacco on daily basis. Smoking rates were higher in individuals having lower levels of education, students studying in university and people who had no income.

Conclusion Providing data on the prevalence and factors associated with smoking among specific populations may offer an improved understanding of the tobacco use patterns as well as it may help in developing interventions or health related policies.

\section{Introduction}

Controlling the use of tobacco is a foremost public health problem. Use of tobacco contributes to major health issues across the globe and in the United Arab Emirates [1]. The evidence on causality for tobacco use as a cause of disease and death has become irrefutable. Tobacco use, is an established risk factor for cardiovascular diseases as well as cancer and is also a public health threat; it tends to jeopardize the health of humans and also adds a financial burden to the smokers [2]. A national agenda by United Arab Emirates includes 10 specific goals to be achieved by 2021, five of which are related to Noncommunicable diseases (NCDs): tackling cardiovascular diseases (CVD), cancer, diabetes, obesity and smoking.

Globally, deaths arising from use of the tobacco are projected to rise in the upcoming years, if continuous successful actions are not being applied to mitigate this surging evolution of smoking habits at the population level. Ministry of Health and Prevention report (2010) indicated that the prevalence of smoking any tobacco product is $21.6 \%$ among men, and $1.9 \%$ among women [3]. Most of the surveys have been formerly commenced, in an attempt to monitor the smoking prevalence among adults. Majority of these survey were not found to be nationwide or representative of the country's adult population. In the light of this, a series of legislative measures have been newly implemented in an effort to reduce tobacco consumption such as treating nicotine addiction, restricting indoor smoking and 
increase in tobacco taxation. Furthermore, there is a dearth of information on the tobacco use burden in the UAE $[4,5]$.

Limited studies have assessed the tobacco use prevalence among adults across UAE [6-10]. Beyond showing that smoking is unhealthy, epidemiologic research also contributes to identifying predictors of smoking behaviour, assess smoking cessation interventions and measuring the effects of anti-smoking regulations. Providing data on the prevalence and factors associated with tobacco use among UAE populations may provide a better understanding of the tobacco use patterns along with assisting in developing interventions or health policies. The objective of the present study was to explore the prevalence and associated risk factors of smoking in a nationally representative sample of the UAE population. The study further aims to study the socioeconomic determinants such as employment, education and income of the UAE population with respect to the status of smoking.

\section{Methods}

\section{Design and Settings}

A cross-sectional data from the national health survey 2018 from the United Arab Emirates was used. United Arab Emirates (UAE) - is a sovereign nation that is constituted as a federal Middle East monarchy, located in the Arabian Peninsula. It is composed of seven emirates (Abu Dhabi, Ajman, Dubai, Fujairah, Ras Al Khaimah, Sharjah, and Umm Al Quwain). Oil is the main source of income and the essential component of its GDP. The oil discovery drove noteworthy industrial and economic development in the UAE, which has impacted the demographic landscape of the nation.

The National Health survey was a population based cross sectional survey conducted by UAE Ministry of Health and Prevention in 2017-2018. The primary targeted population included private households and families. All labour camps and collective households were excluded from the survey. The survey included both local citizens and Non-local residents of UAE. The WHO STEPwise approach to Surveillance of noncommunicable diseases (STEPS) was integrated with survey design.

\section{Sampling/ Sample Size/ Inclusion and exclusion criteria}

The survey was distributed to 10,000 randomly selected households across all 7 Emirates. This sample was designed to produce representative data. A total of 8188 adults (18 years and above) participated in the survey. Of these 4143 were males and 4045 were females. The overall response rate was $87 \%$ among adults' participants. Multi-stage cluster sampling and random probability sampling techniques were used for the purpose of recruiting the participants in the study.

\section{Data collection/ Questionnaire/Instrument}

UAE World Health-Household Survey, questionnaire for persons 18 years and above was used in the study. Formerly validated WHO STEPwise questionnaire comprised of three major items: behavioural and demographic data, and measurements. This instrument was locally adapted and a pilot study, which 
involved15 respondents, was conducted to validate its suitability in the local setting as well as to test the effectiveness of the research process. The demographics included were age groups, gender, and emirate of residence, nationality, marital status, education level, and income (AED). While behavioural questions will include smoking status, smoking categories, types of tobacco products, and prevalence of smoking. Trained research assistants' gathered pertinent data on behavioural and demographic characteristics using the WHO STEPwise questionnaire. The questionnaire was administered face-to-face, using Computer Assisted Personal Interview (CAPI) techniques. The CAPI tool is a digital version of the questionnaires, wherein all the questionnaires were programmed onto an android based application.

\section{Data Analysis}

Data will be entered in a computerized system and analysed by SPSS (the statistical package of the social sciences) version 25. Inferential and descriptive statistics was used for the analysing the data. Proportions (\%) and frequencies $(n)$ were reported for categorical variables. The associations between the demographic variables and smoking were assessed through bivariate analysis or Chi-square test.

\section{Ethical Considerations}

Ethical approval was acquired from Ethical Review Board of the Ministry of Health and Prevention, Dubai. Moreover, the participants were informed about the confidentiality and anonymity of all collected information during the survey. The voluntary nature of the participation in the study was also emphasized. A consent form was reviewed and signed by the respondents during the NHS survey before completing the questionnaire assuring that the collected data would only be used for scientific purpose. The respondents were also informed that the information provided on the questionnaire will remain confidential. Confidentiality was assured of all research information. Ethical considerations were taken into consideration through all research steps.

\section{Results}

Table 1 demonstrates the demographic characteristics of the selected participants. A total of 8188 respondents were included in the study. Mean age of the respondents was 37.9 (SD =11.6), with age range 18 and above. Most of the respondents were males (50.6\%), married (82\%), and had attained at least a University degree (65\%). Almost $33 \%$ of the respondents were unemployed and $46.2 \%$ of them had income more than 20001 AED; whereas, some of the respondents did not report their monthly income. The number of male smokers was significantly higher than the female smokers among all respondents as well as within the Emirati and non-Emirati population. 
Table 1

Demographic characteristics of the participants

\begin{tabular}{|c|c|c|c|}
\hline Variables & $\begin{array}{l}\text { Male } \\
(n=4143)\end{array}$ & $\begin{array}{l}\text { Females } \\
(n=4045)\end{array}$ & $\begin{array}{l}\text { Total } \\
(\mathrm{n}=\mathbf{8 1 8 8})\end{array}$ \\
\hline & n (\%) & n (\%) & $\mathrm{n}(\%)$ \\
\hline \multicolumn{4}{|l|}{ Age group } \\
\hline $18-29$ years & $928,(11.3 \%)$ & $1219(14.9 \%)$ & $2147(26.2 \%)$ \\
\hline $30-44$ years & $1913,(23.4 \%)$ & $2024(24.7 \%)$ & $3937(48.1 \%)$ \\
\hline $45-59$ years & $1051(12.8 \%)$ & $639(7.8 \%)$ & $1690(20.6 \%)$ \\
\hline $60+$ & $251(3.1 \%)$ & $163(2.0 \%)$ & $414(5.1 \%)$ \\
\hline Total & $4143(50.6 \%)$ & 4045 ( 49.4\% ) & $8188(100.0 \%)$ \\
\hline \multicolumn{4}{|c|}{ Emirate of Residence } \\
\hline Abu Dhabi & $1480(35.73 \%)$ & $1202(29.70 \%)$ & $2682(33 \%)$ \\
\hline Dubai & $1696(40.95 \%)$ & 2032 (50.22\%) & 3728 (46\%) \\
\hline Sharjah & $451(10.89 \%)$ & 311 (7.68\%) & $762(9 \%)$ \\
\hline Ajman & $196(4.73 \%)$ & $186(4.59 \%)$ & $381(5 \%)$ \\
\hline Umm al-Quwain & $39(0.95 \%)$ & $33(0.82 \%)$ & $72(1 \%)$ \\
\hline Ras Al Khaimah & $168(4.06 \%)$ & $192(4.73 \%)$ & $360(4 \%)$ \\
\hline Fujairah & $112(2.70 \%)$ & $91(2.26 \%)$ & $204(2 \%)$ \\
\hline \multicolumn{4}{|l|}{ Marital Status } \\
\hline Single & $762(18.40 \%)$ & $399(9.90 \%)$ & 1161 (14\%) \\
\hline Married & $3320(80.10 \%)$ & 3418 (84.50\%) & $6738(82 \%)$ \\
\hline Separated & $23(0.60 \%)$ & $42(1.00 \%)$ & $65(1 \%)$ \\
\hline Divorced & $22(0.50 \%)$ & $63(1.60 \%)$ & $85(1 \%)$ \\
\hline Widowed & $16(0.40 \%)$ & $123(3.00 \%)$ & $139(2 \%)$ \\
\hline \multicolumn{4}{|l|}{ Education Level } \\
\hline No Education & $75(0.9 \%)$ & $91(1.1 \%)$ & $167(2.0 \%)$ \\
\hline Primary & $160(2.0 \%)$ & $147(1.8 \%)$ & 307 (3.7\%) \\
\hline Secondary & $817(10.0 \%)$ & $693(8.5 \%)$ & 1509 (18.4\%) \\
\hline Intermediate & $398(4.9 \%)$ & $379(4.6 \%)$ & 777 (9.5\%) \\
\hline
\end{tabular}




\begin{tabular}{|c|c|c|c|}
\hline Variables & $\begin{array}{l}\text { Male } \\
(n=4143)\end{array}$ & $\begin{array}{l}\text { Females } \\
(n=4045)\end{array}$ & $\begin{array}{l}\text { Total } \\
(\mathrm{n}=\mathbf{8 1 8 8})\end{array}$ \\
\hline University & $2632(32.1 \%)$ & $2690(32.8 \%)$ & $5322(65 \%)$ \\
\hline Postgraduate & $61(0.7 \%)$ & $45(0.6 \%)$ & $107(1.3 \%)$ \\
\hline \multicolumn{4}{|l|}{ Nationality } \\
\hline Emirati & $566(13.70 \%)$ & $563(13.90 \%)$ & $1129(14 \%)$ \\
\hline Non-Emirati & $3577(86.30 \%)$ & $3482(86.10 \%)$ & $7059(86 \%)$ \\
\hline \multicolumn{4}{|l|}{ Type of Employment } \\
\hline Currently Working & $3673(88.66 \%)$ & $1774(43.85 \%)$ & $5447(67 \%)$ \\
\hline Public sector (Government employee) & $698(19.00 \%)$ & $272(15.33 \%)$ & $970(18 \%)$ \\
\hline Private Sector & $2556(69.58 \%)$ & $1348(76.01 \%)$ & $3904(72 \%)$ \\
\hline Semi-state & $215(5.84 \%)$ & $88(4.99 \%)$ & $303(6 \%)$ \\
\hline Self-employed & $185(5.02 \%)$ & $54(3.04 \%)$ & $238(4 \%)$ \\
\hline Informal employment & $20(0.56 \%)$ & $11(0.63 \%)$ & $32(1 \%)$ \\
\hline Unemployed & $470(11.34 \%)$ & $2271(56.15 \%)$ & $2741(33 \%)$ \\
\hline \multicolumn{4}{|l|}{ Monthly income (AED) } \\
\hline Income not reported & $2256(27.6 \%)$ & $1997(24.4 \%)$ & $4253(51.9 \%)$ \\
\hline $0-5000$ & $2(0.0 \%)$ & $0(0.0 \%)$ & $2(0.0 \%)$ \\
\hline $5001-10000$ & $31(0.4 \%)$ & $5(0.1 \%)$ & $36(0.4 \%)$ \\
\hline $10001-15000$ & $45(0.5 \%)$ & $11(0.1 \%)$ & $56(0.7 \%)$ \\
\hline $15001-20000$ & $43(0.5 \%)$ & $19(0.2 \%)$ & $62(0.8 \%)$ \\
\hline 20001 and above & 1765 (21.6\%) & $2014(24.6 \%)$ & 3779 (46.2\%) \\
\hline \multicolumn{4}{|l|}{ Age group } \\
\hline $18-29$ years & $928,(11.3 \%)$ & $1219(14.9 \%)$ & $2147(26.2 \%)$ \\
\hline $30-44$ years & $1913,(23.4 \%)$ & $2024(24.7 \%)$ & $3937(48.1 \%)$ \\
\hline $45-59$ years & $1051(12.8 \%)$ & $639(7.8 \%)$ & $1690(20.6 \%)$ \\
\hline \multicolumn{4}{|l|}{ Smoking status } \\
\hline Current Smokers & $650(15.7 \%)$ & $97(2.4 \%)$ & 747 (9.1\%) \\
\hline Ex-Smoker & $166(4.0 \%)$ & $44(1.1 \%)$ & $210(3 \%)$ \\
\hline
\end{tabular}




\begin{tabular}{|llll|}
\hline Variables & $\begin{array}{l}\text { Male } \\
(\mathbf{n = 4 1 4 3 )}\end{array}$ & $\begin{array}{l}\text { Females } \\
(\mathbf{n = 4 0 4 5 )}\end{array}$ & $\begin{array}{l}\text { Total } \\
\mathbf{( n = 8 1 8 8})\end{array}$ \\
\hline Never-Smoked & $3327(80.3 \%)$ & $3904(96.5 \%)$ & $7231(88 \%)$ \\
\hline Smoking categories & & & \\
\hline Primary smokers & $650(15.7)$ & $97(2.4)$ & $747(9.1 \%)$ \\
\hline Secondary smokers & $68(1.6)$ & $172(4.3)$ & $240(2.9 \%)$ \\
\hline Non-Smokers & $3425(82.7)$ & $3776(93.3)$ & $7201(87.9 \%)$ \\
\hline
\end{tabular}

As shown in Table 1, 747 (9.1\%) of the respondents were current smokers, 210 (3\%) were ex-Smoker, while, 7231 (88\%) never smoked. As per table 2, Around 463 (23.9\%) consumed fewer than 5 cigarette in a day. As can be seen, the most common form of smoked tobacco use was in the form of manufactured Cigarettes followed by Shisha, Medwakh and E-Cigarettes. From 747 respondents who reported the use of tobacco product, $69.8 \%$ were known to be using manufactured cigarettes, $0.5 \%$ used hand rolled cigarettes, and $0.8 \%$ were reported to use pipes full of tobacco and Cigars, cheroots, cigarillos each respectively. $9.1 \%$ were reported to smoke Shisha, $2.3 \%$ used e-cigarettes, and $6.6 \%$ were reported to use Medwakh. Smoking prevalence rises to $9.7 \%$ in households earning 15,001-20,000 AED, and drops to $2.8 \%$ in households earning 5001-10,000 AED ( $p=0.42)$. The highest reported smoking age group was 30-44 (9.8\%) while lowest smoking age group was among elders aged 60+ (5.8\%). Compared to smokers, majority of the non-smokers were in the age group 60 and above.

\section{Secondary Smoking}

Overall, $2.9 \%(n=240)$ of the non-smoking respondents were exposed to passive smoking either at workplace or home. Males' respondents were found to smoke more (15.7\%) than females $(2.4 \%)$. Government employees had the highest prevalence of smoking (13.7\%) compared with semi-state $(12.6 \%)$ and the unemployed participants (2.5\%). Participants who were single used tobacco products more $(14.6 \%)$ compared to the married counterparts (8.2\%). University students had highest prevalence of smoking compared to those in secondary levels of education (19.4\%). 


\begin{tabular}{|ll|}
\hline Table 2: Types of tobacco products used, smoking categories and prevalence. & $\mathbf{N}(\%)$ \\
\hline Prevalence of smoking & $747(9.1 \%)$ \\
Smoking (Yes) & $7441(90.9 \%)$ \\
\hline Smoking (No) & \\
$<5$ cigarettes per day & $23.9 \%$ \\
$5-9$ cigarettes daily & $22 \%$ \\
$10-14$ cigarettes daily & $19.8 \%$ \\
$15-24$ cigarettes daily & $29.1 \%$ \\
$>25$ cigarettes per day & $5.3 \%$ \\
Types of tobacco products used by participants & \\
Manufactured cigarettes & $69.8 \%$ \\
Hand-rolled cigarettes & $0.5 \%$ \\
Pipes full of tobacco & $0.8 \%$ \\
Cigars, cheroots, cigarillos & $0.8 \%$ \\
Number of Shisha/ nargila/ hooka sessions & $9.1 \%$ \\
Medwakh & $6.6 \%$ \\
E-Cigarettes & $2.3 \%$ \\
\hline
\end{tabular}

As demonstrated in Table 3, Gender ( $p=0.001)$, marital status, $(p=0.001)$, age $(p=0.031)$, level of education $(p=0.019)$ and employment status $(p=0.001)$ were significantly associated with smoking. 
Table 3

Association between demographic characteristics and smoking

\begin{tabular}{|c|c|c|c|c|c|}
\hline Variables & Smoke & $\begin{array}{l}\text { Do not } \\
\text { smoke }\end{array}$ & OR & $\mathrm{Cl}(95 \%)$ & $\begin{array}{l}\mathrm{p}- \\
\text { value }\end{array}$ \\
\hline Age (years) & \multirow{2}{*}{$\begin{array}{l}9.2 \\
(197)\end{array}$} & $90.8(1950)$ & 0.613 & \multirow{2}{*}{$\begin{array}{l}0.396- \\
0.948\end{array}$} & 0.031 \\
\hline $18-29$ years & & $90.2(3552)$ & 0.57 & & 0.028 \\
\hline $30-44$ years & $\begin{array}{l}9.8 \\
(386)\end{array}$ & $91.7(1550)$ & 0.683 & $\begin{array}{l}0.373- \\
0.872\end{array}$ & 0.010 \\
\hline $45-59$ years & \multirow{2}{*}{$\begin{array}{l}8.3 \\
(141)\end{array}$} & 94.2 (389) & \multirow[t]{4}{*}{0} & \multirow{2}{*}{$\begin{array}{l}0.437- \\
1.066\end{array}$} & 0.093 \\
\hline $60+$ & & 90.9 (7441) & & & 0 \\
\hline \multirow[t]{2}{*}{ Total } & $5.8(24)$ & & & \multirow{2}{*}{0} & 0.022 \\
\hline & \multicolumn{2}{|l|}{$\begin{array}{l}9.1 \\
(747)\end{array}$} & & & \\
\hline \multirow{3}{*}{$\begin{array}{l}\text { Gender } \\
\text { Male } \\
\text { Female }\end{array}$} & \multirow[t]{2}{*}{$\begin{array}{l}15.7 \\
(650)\end{array}$} & 84.3 (3493) & \multirow[t]{3}{*}{0.132} & \multirow[t]{3}{*}{$\begin{array}{l}0.106- \\
0.165\end{array}$} & 0.001 \\
\hline & & 97.6 (3948) & & & \\
\hline & $2.4(97)$ & & & & \\
\hline \multirow{8}{*}{$\begin{array}{l}\text { Income (AED) } \\
\text { No income } \\
0-5000 \text { AED } \\
5001-10,000 \text { AED } \\
\text { 10,001-15,000AED } \\
\text { 15,001-20,000 AED 20,001 AED - } \\
\text { above }\end{array}$} & \multirow{2}{*}{$\begin{array}{l}9.6 \\
(409)\end{array}$} & 90.4 (3844) & 1.1116 & \multirow{2}{*}{$\begin{array}{l}0.959- \\
1.300\end{array}$} & \multirow[t]{8}{*}{0.42} \\
\hline & & $100(2)$ & NA & & \\
\hline & \multirow{6}{*}{$\begin{array}{l}0.0(0) \\
2.8(1) \\
5.4(3) \\
9.7(6) \\
8.7(328)\end{array}$} & $97.2(35)$ & 0.406 & \multirow{2}{*}{$\begin{array}{l}\text { NA } \\
0.072- \\
2.277\end{array}$} & \\
\hline & & \multirow{2}{*}{$\begin{array}{l}94.6(53) \\
90.3(56)\end{array}$} & 0.512 & & \\
\hline & & & 1.023 & \multirow{2}{*}{$\begin{array}{l}0.146- \\
1.793\end{array}$} & \\
\hline & & \multirow{3}{*}{$91.3(3450)$} & \multirow{3}{*}{0} & & \\
\hline & & & & $\begin{array}{l}0.424- \\
2.472\end{array}$ & \\
\hline & & & & $\begin{array}{l}0.000- \\
0.000\end{array}$ & \\
\hline Marital status & \multirow{2}{*}{$\begin{array}{l}14.6 \\
(170)\end{array}$} & 85.4 (991) & 0.087 & \multirow{2}{*}{$\begin{array}{l}0.022- \\
0.349\end{array}$} & 0.001 \\
\hline Single & & $91.8(6186)$ & 0.168 & & 0.001 \\
\hline Married & $\begin{array}{l}8.2 \\
(551)\end{array}$ & $81.5(53)$ & 0.068 & $\begin{array}{l}0.042- \\
0.669\end{array}$ & 0.011 \\
\hline Separated & 18.5 & $85.9(73)$ & 0.091 & $0.015-$ & 0.001 \\
\hline Divorced & & 98.6 (137) & 0 & & 0.002 \\
\hline Widowed & $\begin{array}{l}14.1 \\
(12)\end{array}$ & & & $\begin{array}{l}0.020- \\
0.410\end{array}$ & 0 \\
\hline & $1.4(2)$ & & & & \\
\hline
\end{tabular}




\begin{tabular}{|c|c|c|c|c|c|}
\hline Variables & Smoke & $\begin{array}{l}\text { Do not } \\
\text { smoke }\end{array}$ & OR & $\mathrm{Cl}(95 \%)$ & $\begin{array}{l}\mathrm{p}- \\
\text { value }\end{array}$ \\
\hline Level of education & $0.7(5)$ & $2.2(162)$ & 3.881 & \multirow{2}{*}{$\begin{array}{l}1.283- \\
11.743\end{array}$} & 0.019 \\
\hline No Education & $4.3(32)$ & $3.7(275)$ & 0.991 & & 0.016 \\
\hline Primary & $\begin{array}{l}19.4 \\
(145)\end{array}$ & $18.3(1365)$ & 1.073 & $\begin{array}{l}0.479- \\
2.048\end{array}$ & 0.98 \\
\hline Secondary & \multirow{2}{*}{$\begin{array}{l}11.6 \\
(87)\end{array}$} & $9.3(690)$ & 0.899 & \multirow{2}{*}{$\begin{array}{l}0.561- \\
2.054\end{array}$} & 0.832 \\
\hline Intermediate & & $65.2(4854)$ & 1.179 & & 0.753 \\
\hline University & $\begin{array}{l}62.6 \\
(468)\end{array}$ & $1.3(107)$ & 0 & $\begin{array}{l}0.462- \\
1.747\end{array}$ & 0.61 \\
\hline Postgraduate & $1.5(11)$ & & & $\begin{array}{l}0.626- \\
2.222\end{array}$ & 0 \\
\hline Employment status & $2.5(56)$ & $97.5(2143)$ & 3.931 & $1.338-$ & 0.001 \\
\hline Unemployed & $\begin{array}{l}13.7 \\
(150)\end{array}$ & $948(86.3)$ & 0.643 & \multirow{2}{*}{$\begin{array}{l}0.223- \\
1.853\end{array}$} & 0.013 \\
\hline Government employee & \multirow{2}{*}{$\begin{array}{l}10.9 \\
(465)\end{array}$} & $89.1(3782)$ & 0.829 & & 0.414 \\
\hline Non-Government employee & & $87.4(291)$ & 0.713 & \multirow[t]{2}{*}{$\begin{array}{l}0.291- \\
2.367\end{array}$} & 0.727 \\
\hline Semi-State & \multirow{2}{*}{$\begin{array}{l}12.6 \\
(42)\end{array}$} & $88.5(238)$ & 0.79 & & 0.545 \\
\hline Self-employment & & $90.5(38)$ & 0 & $\begin{array}{l}0.239- \\
2.130\end{array}$ & 0.677 \\
\hline \multirow[t]{2}{*}{ Informal Employment } & (31) & & & \multirow{2}{*}{$\begin{array}{l}0.260- \\
2.396\end{array}$} & \multirow[t]{2}{*}{0} \\
\hline & $9.5(4)$ & & & & \\
\hline
\end{tabular}

\section{Discussion}

Our study examined the burden of smoking among 18 and above individuals in the United Arab Emirates. It is well known that cigarette smoking is a significant and independent risk factor for premature death, certain types of cancers and cardiovascular disease [11]. We found the current smoking prevalence to be $9.1 \%$ among the selected population whereas, $0.8 \%$ of the respondents smoked tobacco on daily basis. These results were obtained may be due to the effect of epidemiological transition and globalisation [12].

World Health Organization revealed a global increase in cigarette smoking [13]. The prevalence reported in our study was shown to be considerably lower than the national prevalence reported previously in the year 2010 . Around $21.6 \%$ among men and $1.9 \%$ among women respectively [14]. The percentage of smokers over the age of 18 years has gone as low as $9.1 \%$ down from $11.1 \%$ in 2010 [15]. This decline may be due to activating Tobacco Control laws and regulations across UAE, health awareness campaigns, strengthening smoking cessation services, Federal Law No.15 of 2009 regarding Tobacco Control Public health draft law, increasing the number of smoking cessation clinics and levying Excise tax on tobacco products among other initiatives. 
Our results also suggest that University students had highest prevalence of smoking compared to those in secondary levels of education (19.4\%). The prevalence rate reported in our study was lower compared with the results from other studies in Arab countries conducted among health-related students, including $17.2 \%$ in Jordan [16] 46.7\% in Egypt [17] 46\% in Kuwait [18], and 26.3\% in Lebanon [19]. The results of our current study additionally substantiated a documented decline in the smoking prevalence. These results are commendable, since continuous monitoring is performed to sustain the effectiveness of tobacco control policies in the country. Thus, smoking prevalence recorded in this study was less than those reported in some other developing countries. A large cross-sectional study conducted in Abu Dhabi, reported modes of tobacco consumption and prevalence in the UAE. Overall, smoking prevalence reported in males was $24.3 \%$ and $0.8 \%$ in females. Highest prevalence was reported in males aged $20-39$ years. Smoker's mean age was $32.8(\mathrm{SD}=11.1)$ years; "35.7 (SD = 12.1) in females, and 32.7 (11.1) in males." One of the commonest form of tobacco use was cigarette smoking $(77.4 \%)$, which was followed by $15.0 \%$ Midwakh use, $6.8 \%$ shisha (water pipe), and $0.66 \%$ cigar use [20]. While in our study, most common form of smoked tobacco use was in the form of manufactured cigarettes followed by Shisha, Medwakh and E-cigarettes.

Furthermore, our results also suggest that prevalence rate of smoking was affected significantly by family income, which includes the smokers percentage among adults from families with no income was higher than those from high income ones. These results were in conformity with the WHO survey that states that the poorest men were over 2.5 times more likely to smoke than the richest men in numerous countries [21]. A possible reason also could be that individuals with a lower socioeconomic status had more psychosocial, physical, and emotional problems. It should also be noted that not only wealth but other proxies of household socio-economic status - such as single-parent families and low levels of education and employment are also associated with higher prevalence of smoking. The smoking relate factors identified in this study should be taken into account in the adoption of antismoking programmes, that can make them more operational and better capable to influence the behaviours as well as attitudes of smokers.

\section{Strengths And Limitation}

The major strength of the study was its large sample size having a variety of characteristics. Even though a standardised procedure and questionnaire was used in the study, some limitations in the study cannot be ignored. As the study was cross sectional questionnaire-based survey, therefore, results were selfreported that might have introduced some bias or led to under-reporting of the true prevalence of smoking/tobacco use. The cross-sectional nature of the study did not permit us to establish cause and effects of the studied variables. Sampling of patient aged 18 years and above may have led to the underreporting of the tobacco use prevalence among youth, since tobacco use has been reported to rise among younger population. However, a larger sample size gave credence to the results of the study. The study will provide useful epidemiological data to help the decision makers in developing effective interventions that can be implemented across the country. 


\section{Conclusion}

In conclusion, the data from the national health survey helped us to determine the prevalence of smoking among adults in the United Arab Emirates. This study is among the first to detail and provide the baseline information about the prevalence of tobacco use in a nationally representative sample from the United Arab Emirates. The socioeconomic factors significantly associated with smoking are age, sex, marital status, educational level, and employment status. Among the studied age groups, smoking was mostly found among the middle-aged people (30-44-year-old), followed by those in the age group (19-27-yearold). As noted earlier, smoking is more prevalent among males. Regarding the level of education, smoking was more common among university degree holders. Although income was not significantly associated with smoking, it was noted that smoking was commonly found among those with no income. On the other side, smoking was least found among those aged sixty years or more, widowed, those with no education, and those with informal employment among the corresponding categories.

Compared to the pervious screening in 2010, the prevalence of smoking has been reduced, which can be attributed to the restrictions and laws initiated. More educational and awareness campaigns are required among the categories with a high prevalence of smoking. More restrictions can be applied to cigarette smoking, especially for young persons. Moreover, tobacco control measures implemented by the UAE government had a favourable impact on motivating people to quit tobacco use. Our results also showed that some of the socio-demographic factors are associated with smoking among UAE adult population. These factors should therefore be taken into consideration while developing evidence-based prevention programs and interventions that targets at risk groups. However, more awareness about the dangers of tobacco usage should be created. Results of the study may help to inform the tobacco policy agencies about the prevalence and comparison of the use of different tobacco products. Furthermore, strengthening tobacco-control policies and promotion of a comprehensive smoke-free law may help to prohibit smoking in all indoor areas without any exceptions resulting in decreased smoking prevalence in the near future. The strategies should target people throughout the educational and socioeconomic spectrum, in order to ensure that cessation programs as well as smoking prevention can reach the entire population. The data summarized in the study will help the decision-makers to take informed actions in light of robust data to ensure fruitful results.

\section{Abbreviations}

United Arab Emirates (UAE); Non-communicable diseases (NCDs); cardiovascular diseases (CVD); Computer Assisted Personal Interview (CAPI)

\section{Declarations}

\section{Availability of data and materials}


The datasets used and/or analyzed during the current study are available from the corresponding author on reasonable request.

\section{Competing interests}

The authors declare that they have no competing interests.

\section{Ethics approval and consent to participate}

Ethical approval was acquired from Ethical Review Board of the Ministry of Health and Prevention, Dubai.

\section{Consent for publication}

All authors agreed to the publication of this manuscript.

\section{Funding}

None declared

\section{Author's contributions}

HAR drafted the original manuscript after discussion with $A H, \& A Q_{\text {„N }} A Q$ revised the manuscript. $M M$ supported in language editing and wrote the conclusion. AQ collected and analysed the data. All authors read and approved the final manuscript.

\section{Acknowledgement}

This work was supported by the Statistics and Research Center, Ministry of Health and Prevention, Dubai, UAE. We would like to acknowledge Suhair Akhlaq for analysing the data and Ms. Mubarkah Jaber. AlKarbi for the moral support.

\section{References}

1. Cahill K, Stevens S, Perera R, Lancaster T. Pharmacological interventions for smoking cessation: an overview and network meta-analysis. Cochrane Database Syst Rev. 2013;(5):CD009329 doi:10.1002/14651858.CD009329.pub2.

2. Saha SP, Bhalla DK, Whayne TF, Gairola CG. Cigarette smoke and adverse health effects: An overview of research trends and future needs. Int J Angiol. 2007;16(03):77-83. PMID: 22477.

3. National Key Performance Indicators retrieved from https:/ (Accessed on 7/01/2018). 
Vision. 2021. National Key Performance Indicators retrieved from https://www.vision2021.ae/en/nkpi/prevalence-smoking-any-tobacco-product (Accessed on 7/01/2018).

4. Younis FA, Mattar T, Wilson AK. The association between tobacco smoking and reported psychiatric symptoms in an adolescent population in the United Arab Emirates. Social Behavior and Personality: an international journal. 2003 Jan 1;31(5):461-5.

5. Akl EA, Gunukula SK, Aleem S, Obeid R, Jaoude PA, Honeine R, Irani J. The prevalence of waterpipe tobacco smoking among the general and specific populations: a systematic review. BMC public health. 2011 Dec;11(1):244.

6. Aden B, Karrar S, Shafey O, Al Hosni F, Cigarette. Water-pipe, and Medwakh Smoking Prevalence Among Applicants to Abu Dhabi's Pre-marital Screening Program, 2011. Int J Prev Med. 2013;4(11):1290-5.

7. Alblooshi H, Hulse GK, El Kashef A, et al. The pattern of substance use disorder in the United Arab Emirates in 2015: results of a National Rehabilitation Centre cohort study. Subst Abuse Treat Prev Policy. 2016;11(1):19.

\section{10.1371/journal.pone.0039189}

Al-Houqani M, Ali R, Hajat C. Tobacco smoking using Midwakh is an emerging health problemevidence from a large cross-sectional survey in the United Arab Emirates. PloS one. 2012;7(6): e39189. PMID: 22720071; doi: 10.1371/journal.pone.0039189.

9. Obaid HA, Hassan MA, Mahdy NH, et al. Tobacco use and associated factors among school students in Dubai, 2010: intervention study. East Mediterr Health J. 2015;20(12):765-73.

10. Al Shemmari N, Shaikh RB, Sreedharan J. Prevalence of dokha use among secondary school students in Ajman, United Arab Emirates. Asian Pac J Cancer Prev. 2015;16(2):427-30.

11. Saha SP, Bhalla DK, Whayne TF, Gairola CG. Cigarette smoke and adverse health effects: An overview of research trends and future needs. Int J Angiol. 2007 Sep;16(03):77-83.

12. Reubi D. Modernisation, smoking and chronic disease: Of temporality and spatiality in global health. Health place. 2016 May;1:39:188-95.

13. WHO. Tobacco. Factsheet. World health Organization. 2019. Retrieved from https://www.who.int/news-room/fact-sheets/detail/tobacco.

14. Zain AA. Prevention, not cure is focus of UAE's health policy.2016 retrieved from https://www.khaleejtimes.com/nation/uae-health/prevention-not-cure-is-focus-of-uaes-health-policy.

15. MOHAP. National Health Survey results officially announced. 2019. Retrieved from https://www.mohap.gov.ae/en/MediaCenter/News/Pages/2072.aspx.

16. Alomari Q, Barrieshi-Nusair K, Said K. Smoking prevalence and its effect on dental health attitudes and behaviour among dental students. Medical Principles Practice. 2006;15(3):195-9. doi:10.1159/000092181.

17. .Khan AA, Dey S, Taha AH, et al. Attitudes of Cairo University medical students toward smoking: the need for tobacco control programs in medical education. J Egypt Public Health Assoc. 2012;87:1. 
doi:10.1097/01.epx.0000411467.14763.0b.

18. Husain $\mathrm{H}$, Al-Fadhli F, Al-Olaimi F, et al. Is smoking shisha safer than cigarettes: comparison of health effects of shisha and cigarette smoking among young adults in Kuwait. Medical Principles Practice. 2016;25(2):117-22. doi:10.1159/00044241720.

19. Jradi H, Wewers ME, Pirie PR, Binkley PF, Ferketich K. Cigarette and waterpipe smoking associated knowledge and behaviour among medical students in Lebanon. Eastern Mediterranean Health Journal. 2013;19:861-8. doi:10.26719/2013.19.10.861.

20. Al-Houqani M, Ali R, Hajat C. Tobacco smoking using Midwakh is an emerging health problemevidence from a large cross-sectional survey in the United Arab Emirates. PloS one. 2012 Jun;15(6):e39189. 7(.

21. Hosseinpoor AR, Parker LA, Tursan d'Espaignet E, Chatterji S. Socioeconomic Inequality in Smoking in Low-Income and Middle-Income Countries: Results from the World Health Survey. PloS One. 2012;7(8):e42843. 